\title{
Desafios do ensino superior em educação física: considerações sobre a política de avaliação de cursos
}

- Ana Lúcia Padrão dos Santos*

- Antonio Carlos Simões ${ }^{* *}$

\section{Resumo}

crescimento do ensino superior no Brasil apresenta números significativos, especialmente pela participação do setor privado. Os cursos de graduação em Educação Física integram este contexto ao apresentar um crescimento de aproximadamente quatrocentos por cento (400\%) de 1991 a 2004. Neste sentido o maior desafio é ajustar a oferta à manutenção da qualidade. Como em outras áreas a solução encontrada tem sido a regulação governamental através de processos de avaliação de instituições, cursos e alunos. Contudo, neste período a própria área sofreu grandes transformações como a regulamentação da profissão, o surgimento de novas áreas de atuação, a criação dos conselhos de Educação Física e finalmente mudanças nas próprias diretrizes curriculares nacionais, que ainda apresentam algumas indefinições. Neste cenário de ampla transformação a avaliação governamental para credenciamento de novos cursos e renovação de credenciamento dos cursos já existentes precisa ser analisado cuidadosamente através de um extenso processo de diálogo entre todos os envolvidos nos cursos de graduação em Educação Física.

Palavras-chave: Educação superior. Educação física. Avaliação. Políticas educacionais.

\section{Challenges of superior education in physical education: considerations on the politics of evaluation of courses Abstract}

The growth of higher education in Brazil presents significant numbers, especially by the participation of the private sector. The graduate courses of Physical Education integrate this context when presenting approximately a four hundred percent (400\%) of growth. In this direction the biggest challenge is to adjust offers to the maintenance of the quality. As in other areas the solution it has been the governmental regulation through processes of evaluation of institutions, courses and students. However, in this period the

\footnotetext{
Mestre em Educação Física, Universidade de São Paulo (USP); Professora Adjunta da Escola de Educação Física e Esportes, USP. E-mail: ana.padrao@usp.br

** Doutor em Ciências da Comunicação, Universidade de São Paulo (USP); Professor Titular da Escola de Educação Física e Esporte, USP. E-mail: acsimoes@usp.br
} 
area itself suffered great transformations as the professional regulation, the sprouting of new areas of performance, the creation of the Physical Education Council and finally changes in the national curricular guidelines that still presents a lack of definitions. In this scene of huge transformation, the governmental evaluation to give license of new courses and renewal the license for the existing courses, already needs to be analyzed carefully through of an extensive process of dialogue between all the involved ones in the courses of graduation in Physical Education.

Keywords: Higher education. Physical Education. Evaluation. Educational policies.

\section{Desafíos de la educación superior en la Educación Física: consideraciones sobre la política de evaluación de cursos Resumen}

El crecimiento de la educación superior en el Brasil presenta números significativos, especialmente en razón de la participación del sector privado. Los cursos de graduación en Educación Física integran este contexto al presentar aproximadamente cuatrocientos por ciento (400\%) en el crecimiento de 1991 a 2004. En este sentido el desafío más grande es ajustar ofertas al mantenimiento de la calidad. Como en otras áreas la solución unida ha sido la regulación gubernamental con procesos de la evaluación de instituciones, de cursos y de alumnos. Sin embargo, en este período el área de la Educación Física sufrió grandes transformaciones como la regulación de la profesión, el brote de nuevas áreas del funcionamiento, la creación del Consejo de la Educación Física y finalmente cambios en las propias directrices curriculares nacionales, que todavía carecen de algunas definiciones. En esta escena de grande transformación de la evaluación gubernamental para acreditación de nuevos cursos y la renovación de la acreditación de los cursos existentes necesita ser analizada cuidadosamente por un proceso extenso de diálogo con todos los implicados en los cursos de graduación en Educación Física.

Palabras clave: Educación superior. Educación Física. Evaluación. Políticas educativas.

\section{Introdução}

Nas últimas décadas, com o surgimento de um novo panorama educacional, as mudanças no sistema de ensino se acentuaram e o ensino superior não ficou à margem deste processo de intensa transformação. Novos níveis e modalidades de educação, a ampliação do número de docentes, o aumento da oferta de cursos, o maior número de alunos e o surgimento de novas instituições estabeleceram um contexto de crescente demanda e competitividade. Também neste período verificou-se uma extraordinária revolução no campo do conhecimento pelo desenvolvimento de novas formas, meios de produção e disseminação de informações através do uso de modernas tecnologias, não só no âmbito regional ou nacional, mas especialmente em um mundo globalizado. Contudo este processo dinâmico resultou em novos desafios para a educação, entre eles o de estabelecer a harmonia no crescimento do ensino superior, no que diz respeito à conciliação de aspectos quantitativos e qualitativos, além de considerar o papel crucial que a educação tem para o desenvolvimento do país. 
Objetivo deste artigo é fazer uma reflexão crítica sobre a evolução do ensino superior em Educação Física no Brasil, particularmente sobre a política de avaliação de cursos superiores na área e os indicadores usados neste processo.

A importância da compreensão apurada desta realidade é reafirmada pelas várias tentativas, por parte do poder público, de estabelecer mecanismos de avaliação do ensino superior ao longo do tempo.

\section{Considerações gerais sobre a avaliação do ensino superior no Brasil}

A primeira tentativa de criação de um processo formal de avaliação aconteceu em 1976 quando foi criada a Coordenação de Aperfeiçoamento de Pessoal de Nível Superior - CAPES, voltada para a avaliação de cursos e programas de pós-graduação. Posteriormente surgiu uma série de discussões e reflexões sobre a avaliação dos cursos de graduação. O tema central de tais discussões eram as conseqüências do aumento do número de instituições de ensino superior no país e o impacto sobre a qualidade da educação oferecida. Assim, em 1986, foi criado pelo Ministério da Educação - MEC, o Grupo Executivo para a Reforma da Educação Superior - GERES (POLIDORO; MARINHO-ARAUJO; BARREYRO, 2006).

Em função das necessidades sociais emergentes e do próprio desenvolvimento do país a década de 1990 foi caracterizada pela expansão do ensino superior, contudo é possível constatar também neste período o fato de que o poder público apresentava sérias dificuldades para suprir estas demandas.

Seria preciso, mais do que antes, compartilhar com a iniciativa
privada o ônus dessa expansão, cuidando o governo de desenvol-
ver mecanismos de acompanhamento que garantam as condições
mínimas de qualidade das novas instituições e dos respectivos cur-
sos (CAVALCANTE, 2000, p. 12).

Em conseqüência desta expansão surgiu um novo programa, o Programa de Avaliação Institucional das Universidades Brasileiras - PAIUB, que tinha como premissa um processo que incluía a auto-avaliação das instituições e também a participação voluntária das mesmas no programa (POLIDORO; MARINHO-ARAUJO; BARREYRO, 2006). No entanto, desde a Lei de Diretrizes e Bases da Educação Nacional - LDB (BRASIL,1996), outros mecanismos de avaliação foram propostos. Gradativamente foi implementado o Exame Nacional de Cursos - ENC, conhecido popularmente como "provão" e que tinha o intuito de avaliar os conhecimentos dos alunos que estavam prestes a concluir o curso. Tais alunos também respondiam a um questionário socioeconômico que visava a identificar o perfil do aluno no ensino superior brasileiro, assim como a opinião destes alunos sobre seus respectivos cursos. Somava-se ainda a este processo a análise das condições de ensino, a avaliação das condições de oferta e a avaliação institucional dos centros universitários.

Estes processos foram-se modificando ao longo da história e tinham características próprias, refletidas na abordagem da avaliação, mas apesar das várias mudan- 
ças todos estes processos tinham a intenção de obter informações e compreender melhor o ensino superior brasileiro.

Atualmente a avaliação do ensino superior brasileiro está sob a responsabilidade do Sistema Nacional de Avaliação do Ensino Superior - SINAES, instituído pelo Presidente da República na forma da Lei n 10.861 , de 14 de abril de 2004 (BRASIL, 2004a, p. 135):

O SINAES tem por finalidades a melhoria da qualidade da educação superior, a orientação da expansão da sua oferta, o aumento permanente da sua eficácia institucional e efetividade acadêmica e social e, especialmente, a promoção do aprofundamento dos compromissos e responsabilidades sociais das instituições de educação superior, por meio da valorização de sua missão pública, da promoção dos valores democráticos, do respeito à diferença e à diversidade, da afirmação da autonomia e da identidade institucional.

Em sua concepção o SINAES prevê a integração e a participação como princípios centrais de um sistema de avaliação. Para que vários aspectos sejam contemplados nesta perspectiva, o SINAES propõe o Exame Nacional de Desempenho dos Estudantes - ENADE, a avaliação dos cursos de graduação, bem como as avaliações de instituições de ensino superior, ambas realizadas por comissões externas de avaliação designadas pelo INEP e que consultam os dados fornecidos pelas Comissões Próprias de Avaliação de cada instituição, chamadas de CPAs.

Este esforço procura refletir o princípio básico de que a educação é um direito social e um dever do Estado, e, portanto deve ser legitimado com credibilidade através de meios reguladores e de controle advindos do poder público e, contudo, em um processo tão complexo é inevitável que algumas questões se apresentem problemáticas.

Em um país tão extenso geograficamente e caracterizado por ampla diversidade torna-se complexo estabelecer parâmetros adequados para contemplar este universo. $\mathrm{Na}$ tentativa de encontrar a melhor solução para este desafio, o SINAES declara que é "papel irrenunciável do Estado na constituição do sistema nacional de Educação Superior, comprometido com a qualidade, tendo as universidades públicas como referência do sistema" (INEP, 2007,p. 15).

Diante da dificuldade do Estado em se tornar provedor do ensino superior para toda a população, o mesmo tornou-se agente regulador e fiscalizador da educação superior oferecida pelo setor privado e, para isso, criou uma série de parâmetros e indicadores para nortear esta fiscalização.

Segundo o Instituto Nacional de Estudos e Pesquisas Anísio Teixeira - INEP (2006a), a avaliação dos cursos de graduação deve contemplar a análise do corpo docente, do corpo técnico-administrativo, dos projetos pedagógicos do curso, da infra-estrutura física de que um curso dispõe, além da logística do ambiente educacional. 
A estrutura destes critérios para avaliação dos cursos está representada na Figura 1.

\section{INSTRUMENTO DE AVALIAÇÃO DE CURSOS DE GRADUAÇÃO}

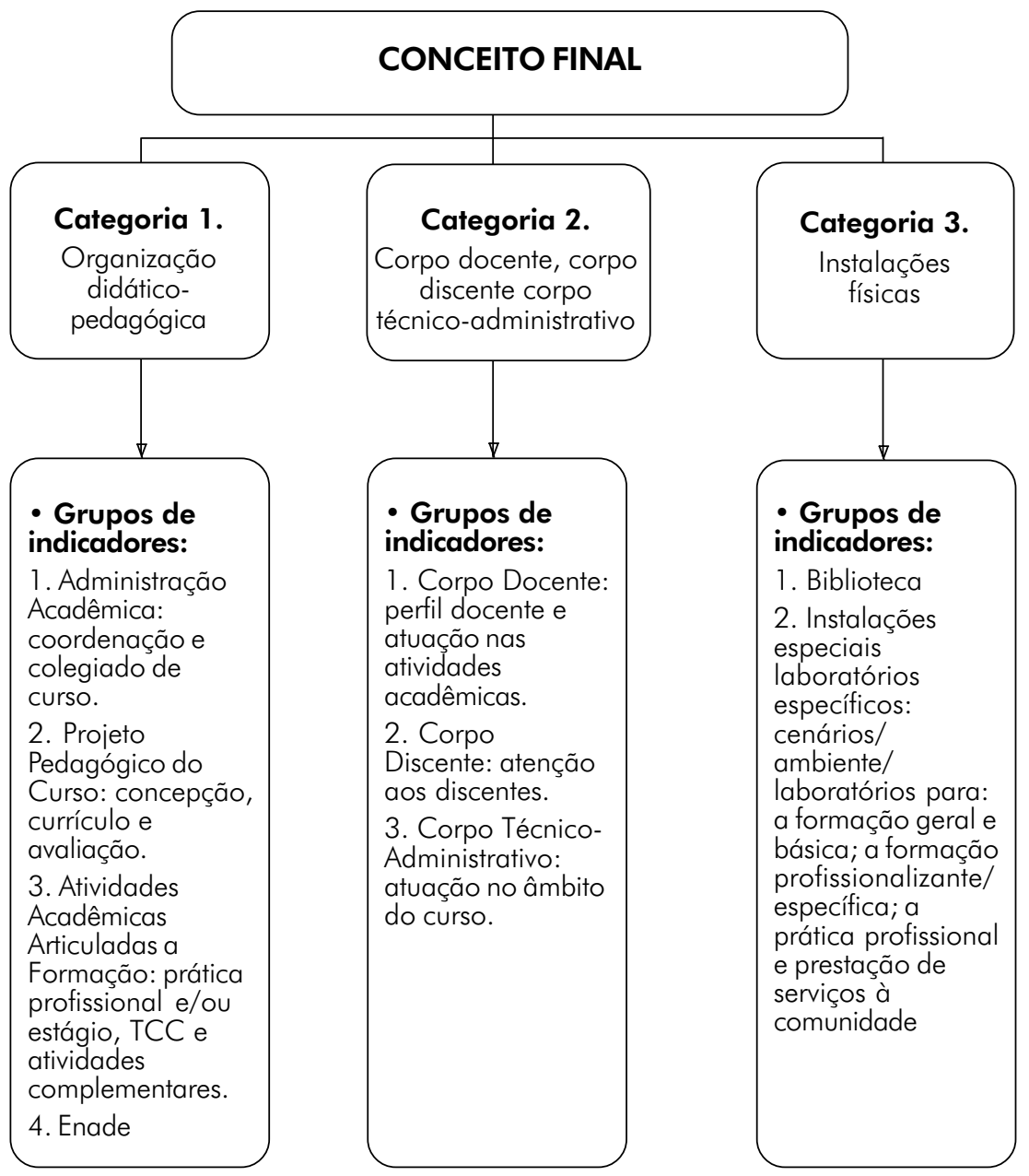

Figura 1 - Matriz orientadora do processo e suas categorias no instrumento de avaliação de cursos de graduação (INEP, 2006a, p. 13).

Além disso, o perfil do avaliador credenciado deve ser adequado e preparado para compreender a realidade onde está atuando e, assim, desempenhar seu papel de maneira a contribuir realmente para a melhoria da qualidade do ensino superior. 
Segundo o INEP (2008), as referências para a escolha de avaliadores estão expressas a seguir:

\begin{tabular}{|c|c|c|c|}
\hline FAMÍLIA & INDICADOR & \multicolumn{2}{|c|}{ PESO DA FAMÍLIA } \\
\hline Competência Acadêmica & $\begin{array}{l}\text { - Orientações concluídas (doutorado) } \\
\text { - Orientações concluídas (mestrado) } \\
\text { - Outras orientações concluídas } \\
\text { - Tempo docência educação superior } \\
\text { - Participação em bancas julgadoras } \\
\text { - Desenvolvimento de material didático- } \\
\text { instrucional } \\
\text { - Pós-doutorado } \\
\text { - Tempo de doutorado }\end{array}$ & 3 & $30 \%$ \\
\hline Competência Científica & $\begin{array}{l}\text { - Trabalhos em eventos nacionais } \\
\text { - Trabalhos em eventos internacionais } \\
\text { - Artigos em periódicos nacionais } \\
\text { - Artigos em periódicos internacionais } \\
\text { Resumos } \\
\text { - Livros publicados } \\
\text { - Capítulos de livros } \\
\text { - Livros organizados } \\
\text { - Pesquisador CNPq }\end{array}$ & 2 & $20 \%$ \\
\hline Competência Tecnológica & $\begin{array}{l}\text { - Participação em projetos } \\
\text { - Coordenação de projetos } \\
\text { - Trabalhos técnicos Resumos } \\
\text { - Livros publicados } \\
\text { - Capítulos de livros } \\
\text { - Livros organizados } \\
\text { - Pesquisador CNPq } \\
\text { - Software, produtos e processos (com } \\
\text { registro) } \\
\text { - Software, produtos e processos (sem } \\
\text { registro) }\end{array}$ & 1 & $10 \%$ \\
\hline $\begin{array}{l}\text { Experiência em Gestão } \\
\text { Acadêmica }\end{array}$ & $\begin{array}{l}\text { - Coordenador de curso } \\
\text { - Diretor de centro ou faculdade } \\
\text { - Pró-reitor ou vice-reitor } \\
\text { - Chefe de departamento } \\
\text { - Reitor } \\
\text { - Presidente de entidade educacional } \\
\text { - Vice-presidente de entidade educacional } \\
\text { - Presidente de entidade científica } \\
\text { - Membro de conselho superior de IES } \\
\text { - Vice-presidente de entidade científica } \\
\text { - Coordenador de CPA } \\
\text { - Membro de CPA }\end{array}$ & 3 & $30 \%$ \\
\hline Atuação em Rede & $\begin{array}{l}\text { Indicado pela própria IES } \\
\text { - Indicado por outra IES } \\
\text { - Redes de colaboradores } \\
\text { - Participação em bancas de doutorado } \\
\text { Particação em bancas de mestrado } \\
\text { Participação em bancas de graduação } \\
\text { Integrante de grupo de pesquisa (CNPq) }\end{array}$ & 1 & $10 \%$ \\
\hline
\end{tabular}

Figura 2 - Indicadores de classificação dos candidatos a avaliador INEP e ponderação para avaliadores de CURSO (INEP, 2008, p. 1). 
Uma vez estabelecidos os parâmetros, o desafio seguinte está em implementar todo este sistema e avaliar o curso superior levando em consideração o contexto em que está inserido, seus aspectos regionais, seus aspectos culturais, a categoria administrativa da instituição de ensino superior e a sua cultura organizacional, além de sua importância e impacto na sociedade à qual pertence.

\section{A educação física neste contexto}

Os cursos superiores em Educação Física acompanharam esta transformação no ensino brasileiro. Em 2006, o INEP lançou a coletânea "A trajetória dos cursos de graduação na saúde: 1991 - 2004" (INEP, 2006c), que apresenta dados e informações da evolução de cada um dos quatorze cursos da área da saúde neste período. O intuito desta publicação é a de que estas informações possam ser proveitosas para o planejamento em cada uma das áreas e que forneça um fundamento consistente para a ação de professores, pesquisadores e gestores do ensino superior em geral.

No Brasil, em 1991 havia 117 cursos de Educação Física e em 2004 este número já tinha passado para 469 cursos, com especial aceleração do crescimento a partir de 1998. Atualmente, segundo o Portal SINAES (INEP, 2007), estão cadastrados no sistema 1031 cursos de graduação em Educação Física.

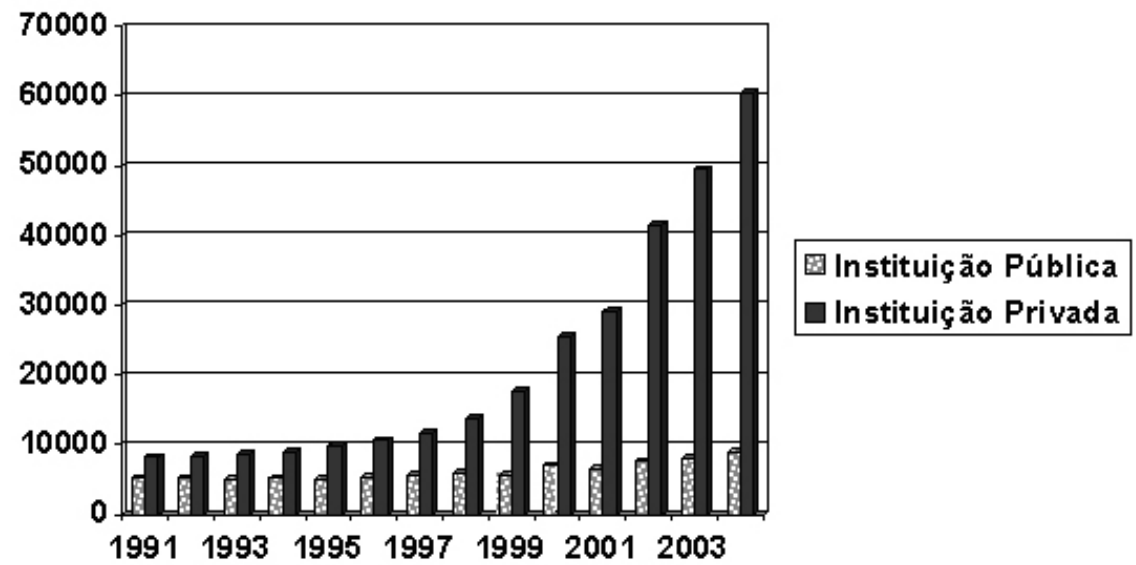

Figura 3 - Evolução do número de cursos de graduação presenciais de Educação Física no Brasil (INEP, 2006a).

A maior concentração destes cursos está na região sudeste que totalizava 225 cursos de graduação em 2004, sendo que, no Estado de São Paulo, havia 120 cursos, ou seja, mais do que em todo o país em 1991. Outro dado extremamente relevante é que, se em 1991 as instituições públicas eram responsáveis por 50,42 \% dos cursos e as instituições privadas por 49,58\%, em 2004 esta relação já se havia alterado significativamente, pois as instituições públicas respondiam por 33,68\%, enquanto as instituições privadas passaram a representar $66,32 \%$ do ensino superior em Educação Física (INEP, 2006c). 
Contudo, o número de instituições talvez não apresente tão claramente a natureza desta transformação. Em relação ao número de vagas oferecidas nos cursos de Educação Física, o crescimento no período foi de 519,07 \%, passando de 13.409 vagas ofertadas em 1991 para 69.603 vagas em 2004 (INEP, 2006c). Vale ressaltar novamente a mudança geral sob o aspecto da categoria administrativa das instituições. Em 1991 o setor público ofertava 38,62\% do total de vagas, e o setor privado ofertava $61,38 \%$. Esta diferença se ampliou de maneira ainda mais decisiva ao longo do tempo, pois em 2004 o setor público passou a representar 12,96\% das vagas, enquanto o setor privado passou a ser responsável por $87,04 \%$ de todas as vagas oferecidas nos cursos superiores em Educação Física no país (INEP, 2006c).

Tais dados parecem evidenciar que o poder público teve dificuldades em atender toda a demanda de formação em Educação Física e, portanto, teve que compartilhar com o setor privado esta responsabilidade.

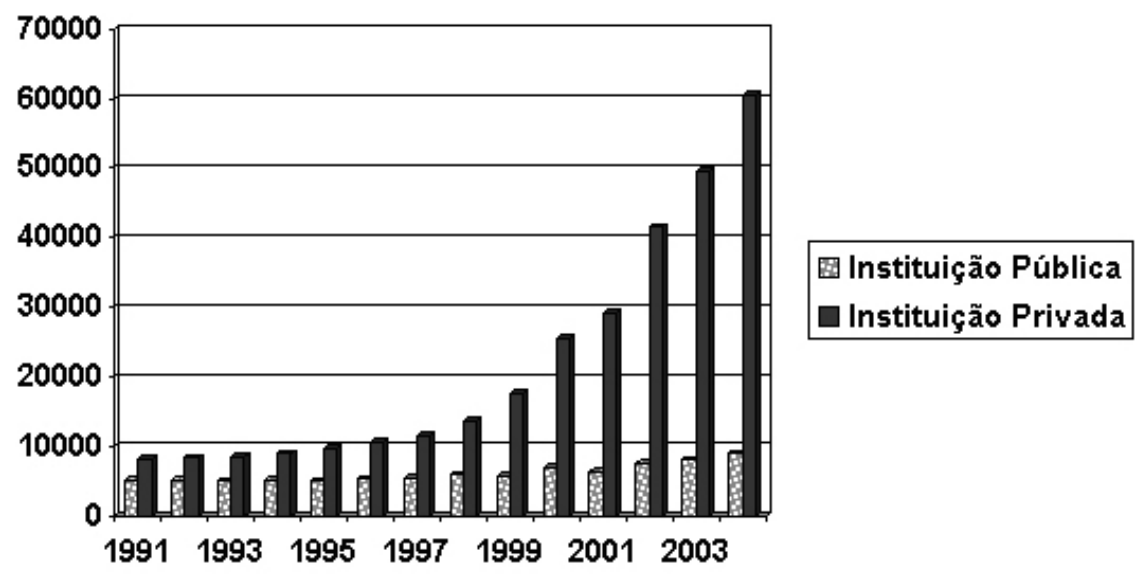

Figura 4 - Evolução de vagas oferecidas nos cursos de graduação presenciais de Educação Física segundo categoria administrativa: Brasil 1991 - 2004 (INEP, 2006c).

Considerando-se esta evolução, é importante refletir sobre a natureza da instituição pública e da instituição privada, quais são os denominadores comuns e quais as divergências, especialmente porque o SINAES se refere ao sistema público como modelo de ensino a ser adotado em todo país. Parece relevante que esta análise seja feita considerando-se a missão, visão e valores institucionais, a extensão e o limite de sua autonomia, sua lógica econômica e todo o impacto que estas variáveis podem produzir nos cursos e na formação educacional de seus alunos.

Em 2004 foi realizado o primeiro Exame Nacional de Desempenho dos Estudantes em Educação Física, e os dados neste processo propiciam uma análise 
mais apurada da formação de profissionais na área de Educação Física em todo o país.

Participaram do processo de avaliação 143.170 estudantes das áreas de Agronomia, Educação Física, Enfermagem, Farmácia, Fisioterapia, Fonoaudiologia, Medicina, Medicina Veterinária, Nutrição, Odontologia, Serviço Social, Terapia Ocupacional e Zootecnia (INEP, 2005).

Do total de alunos convocados pelo INEP, a Educação Física foi a área como o maior número de participantes, representando $21,3 \%$ do total de alunos. (INEP, 2006c). Dos 27.757 alunos de Educação Física, que participaram do ENADE 2004, 72, $1 \%$ eram provenientes de instituições de ensino superior privadas. De todas as áreas avaliadas no Brasil, a Educação Física figurou com o segundo pior desempenho, com 31,2 de média, ficando atrás apenas do Serviço Social com 25,9 de média. $\bigcirc$ curso com melhor desempenho foi Medicina com a média de 54,7.

Outro dado interessante é que a média alcançada pelos alunos em relação à área específica de formação também apresenta uma variação em relação à categoria administrativa da instituição. Alunos provenientes de instituições federais obtiveram o conceito 32,4; alunos provenientes de instituições estaduais obtiveram 29,4; alunos provenientes de instituições municipais obtiveram 27,1 e alunos de instituições privadas ficaram com o conceito 26,4 o que representa a nota mais baixa (INEP, 2006c).

Outro aspecto a considerar é a evolução da área e as profundas transformações que ocorreram na Educação Física nas últimas décadas. Apesar da atuação em Educação Física ter registros de atividades características da área desde o século XVIII, foi apenas através da Lei nº 9.696 (BRASIL, 1998), que a Educação Física foi reconhecida como profissão.

A partir deste momento iniciaram-se a organização do Conselho Federal de Educação Física e dos Conselhos Regionais de Educação Física, conseqüentemente as discussões sobre a atuação profissional tornaram-se mais intensas. Além disso, o perfil profissional pretendido nos cursos superiores de Educação Física também começou a ser questionado. Na última década surgiu a Carta Brasileira de Educação Física (CONSELHO FEDERAL DE EDUCAÇÃO FÍ́SICA, 2000), que faz uma declaração a respeito das perspectivas para Educação Física no século XXI, a Resolução $\mathrm{n}^{\circ}$. 46/2002 (CONSELHO FEDERAL DE EDUCAÇÃO FÍSICA, 2002), que dispõe sobre a intervenção do profissional de Educação Física, suas competências e seu campo de atuação profissional e a Resolução nº. 56/2003 (CONSELHO FEDERAL DE EDUCAÇÃO FÍSICA, 2003), que dispõe sobre o Código de Ética dos Profissionais registrados no sistema CONFEF/CREFs.

Toda esta transformação no campo da atuação profissional não passou à margem das diretrizes curriculares para os cursos de graduação em Educação Física. Até 2004, os cursos de Educação Física tinham como referência a Resolução CFE n. 3, de 16 de junho de 1987 (CONSELHO FEDERAL DE EDUCAÇÃO, 1987), para estru- 
turação de cursos superiores na área, porém em virtude destas significativas transformações, a Comissão da Câmara de Educação Superior do Conselho Nacional de Educação aprovou o Parecer CNE/CES nº. 58, de 18 de fevereiro de 2004 (CONSELHO NACIONAL DE EDUCAÇÃO, 2004), que culminou com a instituição das diretrizes curriculares nacionais para os cursos de graduação em Educação Física, por meio de aprovação da Resolução CNE/CES n. 7, de 31 de março de 2004 (CONSELHO NACIONAL DE EDUCAÇÃO, 2004). Nesta Resolução há a distinção entre o curso de formação de professores da educação básica, licenciatura plena em Educação Física e o curso de graduação em Educação Física, o qual hoje é conhecido geralmente por bacharelado em Educação Física. Há de se ressaltar, ainda, que nesta resolução está o Artigo 14, o qual declara que "a duração do curso de graduação em Educação Física será estabelecida em Resolução específica da Câmara de Educação Superior", decisão que continua pendente até os dias atuais e que tem provocado uma série de incertezas e conflitos nas decisões relativas ao ensino superior em Educação Física (CONSELHO NACIONAL DE EDUCAÇÃO, 2004, p. 19).

\section{Análise dos indicadores usados para avaliação dos cursos superiores e a educação física}

Considerando-se todos estes aspectos é fundamental uma reflexão sobre o processo de avaliação nos cursos superiores em Educação Física.

Os dados apresentados sugerem que transformações importantes estão acontecendo tanto na preparação profissional como na atuação profissional. Para assegurar a qualidade deste processo há um novo sistema de avaliação do ensino superior que também está sendo implementado.

Neste sentido, assegurar que todas estas variáveis venham a convergir para a obtenção da qualidade do ensino superior em Educação Física parece ser um grande desafio.

\section{Análise dos indicadores relacionados à organização didático-pedagógica}

A primeira categoria de análise para a avaliação diz respeito à organização didático-pedagógica. Os indicadores analisam a coordenação de curso, a atuação do colegiado de curso, o projeto pedagógico, as atividades acadêmicas articuladas a formação e o ENADE (INEP , 2006a).

Um aspecto sensível na análise destes indicadores é o tempo que o coordenador de curso e os professores têm disponível, fora do horário de aula, para estruturação e planejamento de atividades, a vivência do próprio ambiente acadêmico, assim como o estudo e assimilação das próprias mudanças que estão acontecendo na área de Educação Física.

Segundo o INEP (2006a), o avaliador deve estar atento ao fato de que o envolvimento do coordenador e dos professores com a construção do projeto pedagógi- 
co do curso, bem como sua participação na instituição está além das horas em sala de aula.

Neste sentido, os próprios dados do INEP (2008) parecem sugerir que medidas devem ser tomadas no sentido de diminuir a diferença entre a situação ideal e a situação real, como apresenta a figura a seguir.

\begin{tabular}{|l|c|c|c|c|}
\hline $\begin{array}{l}\text { Categoria } \\
\text { das IES }\end{array}$ & $\begin{array}{c}\text { Funções } \\
\text { docentes } \\
\text { em exercício }\end{array}$ & $\begin{array}{c}\text { Regime } \\
\text { de trabalho } \\
\text { integral }\end{array}$ & $\begin{array}{c}\text { Regime } \\
\text { de trabalho } \\
\text { parcial }\end{array}$ & $\begin{array}{c}\text { Regime } \\
\text { de trabalho } \\
\text { horista }\end{array}$ \\
\hline PRIVADA & 194.471 & 32.802 & 49.019 & 120.020 \\
\hline PÚBLICA & 98.033 & 77.678 & 18.635 & 7.806 \\
\hline
\end{tabular}

Figura 5 - Funções docente em exercício segundo a categoria da instituição de ensino superior (INEP, 2008).

Ainda na primeira categoria é avaliado o Projeto Pedagógico do Curso que deve estar em consonância com o Projeto Pedagógico Institucional - PPI, e com Projeto de Desenvolvimento Institucional - PDI, e, para isso, é preciso que o corpo docente como um todo tenha oportunidade de aprimorar seus conhecimentos sobre estrutura e funcionamento do ensino superior e participar da construção das diretrizes gerais da instituição de ensino. Este processo deve fornecer sustentação para a construção de um projeto pedagógico do curso coerente com a instituição.

Mesmo assim, ainda há dificuldades a serem superadas e que dependem de outras instâncias. As mudanças na legislação que trata da preparação profissional e atuação profissional em Educação Física ainda carece de ajustes.

Dois problemas emblemáticos desta situação surgem no cumprimento dos estágios supervisionados. Na licenciatura em Educação Física, o aluno deve cumprir quatrocentas (400) horas de estágios supervisionados. Parte significativa das vagas ofertadas nos cursos está destinada ao período noturno e, neste horário, a própria legislação educacional não prevê aulas de Educação Física nas escolas. Para o aluno que freqüenta o período noturno e trabalha durante o dia, há um obstáculo difícil de ser superado, pois no horário em que ele deveria estagiar não há aulas de Educação Física nas escolas. Esse problema afeta também a própria supervisão de estágio que fica comprometida.

Outro aspecto relevante é que, em virtude do recente reconhecimento da profissão, ainda existe um número significativo de pessoas que atuam na área sem formação no ensino superior, inclusive os provisionados em Educação Física, que são "os que até a data do início da vigência desta lei, tenham comprovadamente exercido atividades próprias dos Profissionais de Educação Física, nos termos a serem estabelecidos pelo Conselho Federal de Educação Física" (BRASIL, 1998). Isto significa que 
um estudante do curso de Educação Física pode ter seu estágio supervisionado por uma pessoa que não tem formação em nível superior.

\section{Análise dos indicadores relacionados ao corpo docente, ao corpo discente e ao corpo técnico- administrativo}

Os professores que hoje atuam no ensino superior tiveram sua formação acadêmica em um currículo que abarcava todas as formas de atuação profissional em Educação Física, o que dificulta em alguns casos a distinção dos conteúdos próprios e específicos da licenciatura e dos conteúdos próprios e específicos do bacharelado.

Este processo demanda um profundo amadurecimento por parte dos próprios professores dos cursos de Educação Física, para que o Projeto Pedagógico reflita nesta concepção e possa abordar de maneira satisfatória quais as similaridades, diferenças e a profundidade de conhecimentos necessários em cada uma das formas de atuação profissional. Neste sentido a competência do corpo docente é fator imprescindível à oferta de um ensino de qualidade.

Muitas instituições de ensino superior restringem ao mínimo o número de professores com titulação por questões econômicas que envolvem remuneração e plano de carreira. Professores com titulação em outras áreas que lecionam disciplinas comuns como anatomia, fisiologia entre outras são contabilizados como professores do curso de Educação Física com titulação. Isto causa um impacto direto na formação dos alunos, em especial no que diz respeito à orientação de trabalhos de conclusão de curso e, no caso das universidades, na própria adequação da relação entre ensino, pesquisa e extensão.

Este problema da titulação fica mais evidente ainda quando se analisam as informações fornecidas pela Coordenação de Aperfeiçoamento de Pessoal de Nível Superior - CAPES (2007), que aponta apenas vinte programas de Mestrado em Educação Física e em relação ao doutorado, são apenas nove programas de doutorado em todo o país.

É importante ressaltar que existem 1031 cursos de graduação em Educação Física no Brasil. (INEP, 2008) Estes números estabelecem uma relação de um programa de mestrado para cada cinqüenta e um cursos de graduação, e um programa de doutorado para cada cento e quatorze cursos de graduação. Em muitos casos a dificuldade de acesso a cursos de pós-graduação na área faz com que mesmo os professores de Educação Física procurem obter a titulação em outras áreas, e isto, muitas vezes, contribui para uma descaracterização da própria Educação Física.

Neste momento histórico da área, torna-se um desafio harmonizar toda esta diversidade e conseguir a sinergia necessária para proporcionar uma formação de qualidade ao aluno que preserve a identidade da profissão. 


\section{Análise dos indicadores relacionados às instalações físicas}

A última categoria de indicadores de avaliação diz respeito à biblioteca, às instalações especiais e específicas relacionadas à formação geral, a formação específica, à prática profissional e à prestação de serviços à comunidade (INEP, 2006a).

Basicamente a análise destes indicadores pode ser simples, desde que os indicadores anteriores estejam bem definidos e adequados.

Contudo, é necessário ponderar que são dispendiosos para as instituições os investimentos em instalações físicas como, por exemplo, laboratórios de fisiologia do exercício, laboratório de cineantropometria, laboratório de práticas pedagógicas, laboratório de comportamento motor, laboratório de psicologia do esporte, laboratório de biomecânica, e ainda quadra externa, quadra coberta, piscina, pista de atletismo, salas específicas e outros espaços descritos no Manual de Avaliação das Condições de Ensino do Curso de Educação Física (INEP, 2002).

instrumento atual é mais genérico em relação às especificações, mas talvez gere ainda mais controvérsia, pois pode permitir diferentes interpretações do que significa uma infra-estrutura adequada (INEP, 2006a).

A gestão destes espaços e a sua adequação aos princípios de ensino, pesquisa e extensão, além da sustentabilidade econômica do próprio curso parece ser um desafio bastante complexo.

\section{Perspectivas conclusivas}

Apontados tais desafios é necessário pensar de que maneira todo este processo de avaliação pode promover a melhoria da qualidade de ensino nos cursos superiores de Educação Física. Certamente este é um assunto complexo e seria difícil delimitar caminhos definitivos, mas alguns aspectos parecem ser prementes.

Seria de grande valia uma definição legal sobre as diretrizes curriculares, especialmente no que diz respeito à carga horária mínima e ao tempo de duração de cada habilitação. Neste sentido, uma diretriz mais clara sobre a formação de professores, ou seja, a licenciatura, e a formação de graduados, ou seja, o bacharelado, facilitariam a construção de projetos pedagógicos mais consistentes. Além disso, o alinhamento do pensamento do próprio Ministério da Educação e do Conselho Federal de Educação Física traria mais coerência a tais projetos, pois apesar da distinção de funções entre estas duas instituições, seja a determinação de diretrizes curriculares, seja a fiscalização dos profissionais, há uma interface no processo de formação e atuação profissional.

Além disso, é importante ressaltar que a avaliação dos cursos superiores em Educação Física é um aspecto fundamental para a melhoria da qualidade, porém não suficiente. As medidas efetivas adotadas após este diagnóstico é o que realmente poderá trazer benefícios à área e este aspecto deve ser tratado com rigor. 
A qualidade almejada no ensino superior em Educação Física somente será possível quando houver um diálogo claro entre todos os envolvidos diretamente no ensino superior, como alunos, docentes, gestores, legisladores, avaliadores, setor público e setor privado. Além disso, é essencial esclarecer a toda sociedade o que é a Educação Física atual e quais os rumos na formação de seus profissionais.

\section{Referências}

BRASIL. Lei n. 9.394, de 20 de dezembro de 1996. Estabelece as diretrizes e bases da educação nacional. Diário Oficial [da República Federativa do Brasil], Brasília, DF, 23 dez. 1996.

. Lei $n^{\circ}$. 9.696, de $1^{\circ}$ de setembro de 1996. Dispõe sobre a regulamentação da profissão de Educação Física e cria os respectivos Conselho Federal e Conselhos Regionais de Educação Física. Diário Oficial [da República Federativa do Brasil], Brasília, DF, 2 set. 1998.

. Lei nº 10.861, de 14 de abril de 2004. Institui o Sistema Nacional de Avaliação da Educação Superior. Diário Oficial [da República Federativa do Brasil], Brasília, DF, 15 mar. 2004a.

BRASIL. Resolução n. 7, de 31 de março de 2004. Institui as Diretrizes Curriculares Nacionais para os cursos de graduação em Educação Física, em nível superior de graduação plena. Diário Oficial [da República Federativa do Brasil], Brasília, DF, 5 abr. $2004 b$.

CAVALCANTE, J. F. Educação superior: conceitos, definições e classificações. Brasília, DF: INEP, 2000.

CONSELHO FEDERAL DE EDUCAÇÃO. Resolução CFE n. 3, de 16 de junho de 1987. Fixa os mínimos de conteúdos e duração a serem observados nos cursos de graduação em Educação Física. Diário Oficial [da República Federativa do Brasil], Brasília, DF, 22 jun. 1987.

CONSELHO FEDERAL DE EDUCAÇÃO FÍSICA. Carta Brasileira de Educação Física. Rio de Janeiro, 2000.

Resolução $n^{\circ}$. 46, de 18 de fevereiro de 2002. Dispõe sobre a Intervenção do Profissional de Educação Física e respectivas competências e define os seus campos de atuação profissional. Saúde em Movimento, Rio de Janeiro, 2002. Disponível em: <http://www.saudeemmovimento.com.br/conteudos/ conteudo_exibel.asp?cod_noticia=605 >. Acesso em: 19 maio 2008.

. Resolução $n^{\circ}$. 56, de 18 de agosto de 2003. Dispõe sobre o Código de Ética do Profissional de Educação Física. CONFEF, Rio de Janeiro, 2003.

Disponível em: <http://www.confef.org.br/extra/resolucoes/ conteudo.asp?cd_resol=103>. Acesso em: 19 maio 2008. 
CONSELHO NACIONAL DE EDUCAÇÃO. Câmara de Educação Superior. Parecer CES/CNE n. 58, de 18 de fevereiro de 2004. Diretrizes curriculares para o curso de graduação em Educação Física. Diário Oficial [da República Federativa do Brasil], Brasília, DF, 4 mar. 2004.

COORDENAÇÃO DE APERFEIÇOAMENTO DE PESSOAL DE NÍVEL SUPERIOR. Mestrados e doutorados reconhecidos. Brasília, DF, 2007. Disponível em: <http:// www.capes.gov.br/sobre/estatistica/> Acesso em: 26 abr. 2008.

INEP. Avaliação dos cursos de graduação: instrumento. Brasília, DF, 2006a.

. Avaliadores do BASis. Brasília, DF, 2006b. Disponível em:

<http://www.inep.gov.br/download/condicoes_ensino/2006

AVALIADORES_BASis_INFORMACOES.pdf> . A Acesso em: 22 abr. 2008.

Brasília, DF, 2002.

Manual de avaliação das condições de ensino de educação física.

. Resumo técnico: ENADE 2004. Brasília, DF, 2005.

. Sistema Nacional de Avaliação da Educação Superior: da concepção à regulamentação. Brasília, DF, 2007. Disponível em: <http://sinaes.inep.gov.br/ sinaes/>. Acesso em: 26 abr. 2008.

. A trajetória dos cursos de graduação na saúde: 1991-2004: educação física. Brasília, DF, 2006 c.

POlIDORO, M. M.; MARINHO-ARAUJO, C. M.; BARREYRO, G. B. Sinaes: perspectivas e desafios na avaliação da educação superior brasileira. Ensaio: avaliação e políticas públicas em educação, Rio de Janeiro, v. 14, n. 53, p. 425436, out./dez. 2006.

Recebido em: 09/10/2007

Aceito para publicação em: 06/05/2008 